\title{
OCT4 Expression Enhances Features of Cancer Stem Cells in a Mouse Model of Breast Cancer
}

\author{
Ran-Ju Kim and Jeong-Seok Nam* \\ Laboratory of Tumor Suppressor, Lee Gil Ya Cancer and Diabetes Institute, Gachon University of Medicine and Science, \\ Incheon, Republic of Korea
}

\begin{abstract}
The cancer stem cell (CSC) hypothesis proposes that CSCs are responsible for metastasis and disease recurrence. Therefore, targeting CSCs has the potential to significantly improve outcomes for cancer patients. The OCT4 transcription factor gene is a master gene that plays a key role in the self-renewal and pluripotency of stem cells. In this study, we introduced an OCT4 reporting vector into 4T1 mouse breast cancer cells and sorted OCT4 high and OCT4 low cell populations. We then determined whether OCT4 expression is associated with maintenance and expansion of CSCs. We found that OCT4 ${ }^{\text {high }} 4 \mathrm{~T} 1$ cells have an increased ability to form tumorsphere and a high expression of stem cell markers such as Sca-1, CD133, CD34, and ALDH1, when compared with OCT4 ${ }^{\text {low }} 4 \mathrm{~T} 1$ cells. In addition, OCT4 ${ }^{\text {high }} 4 \mathrm{~T} 1$ cells have greater tumorigenic potential in vivo. These findings suggest that OCT4 expression may be a useful target for stem cell-specific cancer therapy.
\end{abstract}

Key words: Cancer stem cell, OCT4, breast cancer

Received 6 May 2011; Revised version received 6 June 2011; Accepted 7 June 2011

The cancer stem cell (CSC) hypothesis proposes that CSCs, which constitute a small population of cells within a tumor, are able to self-renew and to give rise to diverse cellular progeny. Indeed, CSCs may be responsible for the escape of tumors from conventional therapies, resulting in residual CSCs that can lead to disease recurrence and metastasis [13]. Therefore, CSC-specific therapies might prevent cancer relapse and completely destroy cancer at its root.

The OCT4 (also known as POU5F1) transcription factor gene is known as a master pluripotency gene $[4,5]$. Kim and colleagues showed that OCT4 alone is sufficient to directly reprogram adult mouse neural stem cells to pluripotent stem (iPS) cells [6]. Clinical studies have shown that tumors with intense expression of the OCT4 stem cell marker are associated with further disease progression, greater metastasis, and shorter cancer-related survival compared with tumors with moderate and low OCT4 expression [7]. Furthermore, OCT4 is reported to be a core regulator of stem cell self- renewal and differentiation, and was recently validated as a CSC target [8]. Based on these findings, our study attempts to identify the CSC population characterized by the OCT4 phenotype among 4T1 mouse breast cancer cells. To this end, we stably infected 4T1 cells with a retroviral particle which contains the mouse OCT4 promoter and drives expression of red fluorescent protein (RFP). The goal was to determine whether targeting of OCT4 expression is a feasible strategy for stem specific cancer therapy in a rigorously defined mouse 4T1 breast tumor model.

\section{Materials and Methods}

\section{Cell culture}

Mouse breast cancer cell lines (67NR and 4T1) and human breast cancer cell lines (MCF-7, T-47D, MDA-MB-231, and Hs578T) were cultured in DMEM (Invitrogen, Grand Island, NY, USA) containing $10 \%$ FBS and $1 \%$ penicillin /streptomycin

*Corresponding author: Jeong-Seok Nam, Lee Gil Ya Cancer and Diabetes Institute, Gachon University of Medicine and Science, 7-45 Songdo-dong, Yeonsu-ku, Incheon 406-840, Korea

Tel/Fax: 82-32-899-6072/82-32-899-6350; E-mail: namjs@gachon.ac.kr

This is an Open Access article distributed under the terms of the Creative Commons Attribution Non-Commercial License (http://creativecommons.org/licenses/ by-nc/3.0) which permits unrestricted non-commercial use, distribution, and reproduction in any medium, provided the original work is properly cited. 
(Invitrogen), as previously described [9-11]. The 4T1-LucOCT4 cell line was established by infection of 4T1-Luc cells (Caliper Life Sciences, Hopkinton, MA, USA) with a mouse OCT4-pRFPZeo packaged virus particle (System Biosciences, Mountain View, CA, USA) according to the manufacturer's protocol. Stable transfectants were selected by incubation with zeocin (300 mg/mL, Invitrogen), and OCT4 expression was determined using a fluorescent microscope (Carl Zeiss, Thornwood, NY, USA).

\section{Flow cytometry}

FACS analysis and sorting were performed using a FACS Calibur and FACSAria (Becton Dickinson, Franklin Lakes, NJ, USA), respectively. FACS data were analyzed using Flowjo software (Tree Star, Ashland, OR, USA). The Aldefluor kit (Stem Cell Technologies, Vancouver, Canada) was used to isolate a population with high aldehyde dehydrogenase (ALDH) enzymatic activity, according to the manufacturer's instructions. The following antibody was used: OCT4 (Abcam, Cambridge, MA, USA). An APC-conjugated rabbit IgG antibody (Molecular Probes, Eugene, OR, USA) was used for visualization.

\section{Tumorsphere culture}

Tumor sphere culturing was performed as previously described [12,13]. After 7 to 10 days of culturing, wells were examined under an inverted microscope at x50 magnification, and the number and diameter of spheres was determined for independent fields per well using the Image-Pro Plus program (Media Cybernetics, Bethesda, MD, USA).

\section{In vivo limiting dilution assay}

All animals were maintained according to IACUC approved protocols of the Lee Gil Ya Cancer and Diabetes Institute, Korea. For titration experiments, the left and right thoracic (\#2) mammary fat pads (m.f.p.) of anesthetized 7-week-old female Balb/c mice (Orient Charles River Technology, Seoul, Korea) were surgically exposed and sorted $4 \mathrm{~T} 1$ cells were inoculated into m.f.p. in a $50 \mathrm{~mL}$ volume ( $n=3 /$ group). Tumor incidence was assessed via in vivo bioluminescence measurement using an IVIS Imaging System (Caliper Life Sciences). For luciferase detection, $150 \mathrm{mg} / \mathrm{mL}$ D-luciferin (Caliper Life Sciences) in PBS was injected intraperitoneally before imaging. Photometric measurement of tumors was done by Living Image software (V. 3.1.0, Caliper Life Sciences).

\section{Quantitative reverse-transcription-polymerase chain reaction (RTQ-PCR) \\ RTQ-PCR for quantification of CDNA was performed using}

SYBR green PCR master mix (Applied Biosystems, Foster City, CA, USA) and the ABI 7300 real-time PCR system according to the manufacturer's instructions. The quantitative RT-PCR was done in triplicate. Mouse mRNA levels were normalized with mouse hypoxanthine-guanine phosphoribosyltransferase (HPRT). The primer sets used in this study were as follows: OCT4: 5'-GCATTCAAACTGAGGCACCA-3' (forward) and 5'AGCTTCTTTCCCCATCCCA-3' (reverse); Sca-1: 5'-TCA GTC CTC CTG CAG ACC TT-3' (forward), 5'-ACTCCCACCTTGGA GCTTCT-3' (reverse); ALDH1: 5'-GCTAGCTACAATCGAGG CACTCA-3' (forward), 5'-GCA GCCTCCTAAATCCGACA-3' (reverse); CD133: 5'-CACTTCATCCCACTGCCAAA-3' (forward), 5'-TGACACTGAACGTAATCCCCAT (reverse); CD34: 5'AAAGGCCAATGTGACCCGA-3' (forward), 5'-TCCCACTTTC CTCCATACCAC-3' (reverse); CD90: 5'-TCCAAGCCCTGGAC TTCA TTT C-3' (forward), 5'-CCGTTT CTCCCCATGTTCT GAG-3' (reverse); HPRT: 5'-GCCTAAGATGAGCGCAA GTTG3' (forward), 5'-TACTAGGCAGATCGCCACAGG-3' (reverse).

\section{Statistical analysis}

All experiments were done 3 or more times, and the results are expressed as mean \pm SD. Statistical analyses of these data were done using an unpaired Student's t-test for parametric analysis or the Mann-Whitney $U$ test for nonparametric analysis.

\section{Results}

\section{The $\mathrm{ALDH}^{\text {pos }}$ CSC population has a high OCT4 expression}

The expression of ALDH as assessed by the Aldefluor assay has been recognized as a marker for malignant stem cells in breast cancers [14]. To evaluate OCT4 expression in the CSC population characterized by high ALDH activity, we compared the expression of OCT4 in $\mathrm{ALDH}^{\text {neg }}$ and $\mathrm{ALDH}^{\text {pos }}$ cell population sorted from $4 \mathrm{~T} 1$ cells. RTQ-PCR analysis showed a significant increase ( 3.3 -fold) of OCT4 mRNA expression in $\mathrm{ALDH}^{\mathrm{pos}} 4 \mathrm{~T} 1$ cells (Figure 1A). To confirm the correlation between ALDH activity and OCT4 expression, we examined OCT4 expression in $\mathrm{ALDH}^{\text {neg }}$ and $\mathrm{ALDH}^{\text {pos }}$ cell population from various mouse and human breast cancer cell lines. FACS analysis showed that expression of OCT4 significantly increased (3.3- to 9.5-fold) in $\mathrm{ALDH}^{\text {pos }}$ cell population compared with $\mathrm{ALDH}^{\text {neg }}$ cell population of breast cancer cell lines (Figure 1B).

\section{OCT $4^{\text {high }} 4 \mathrm{~T} 1$ cell population has high tumorsphere forming ability \\ It has been reported that cancer stem-cell like cells can}


A.

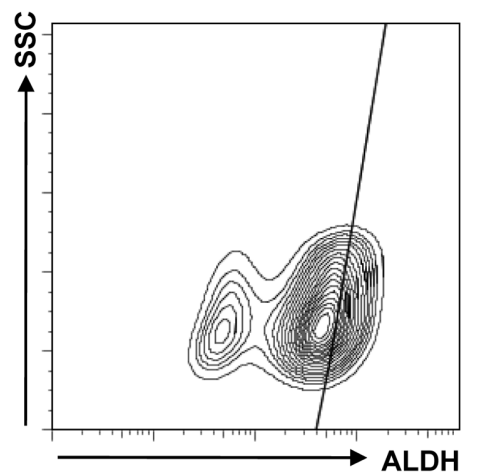

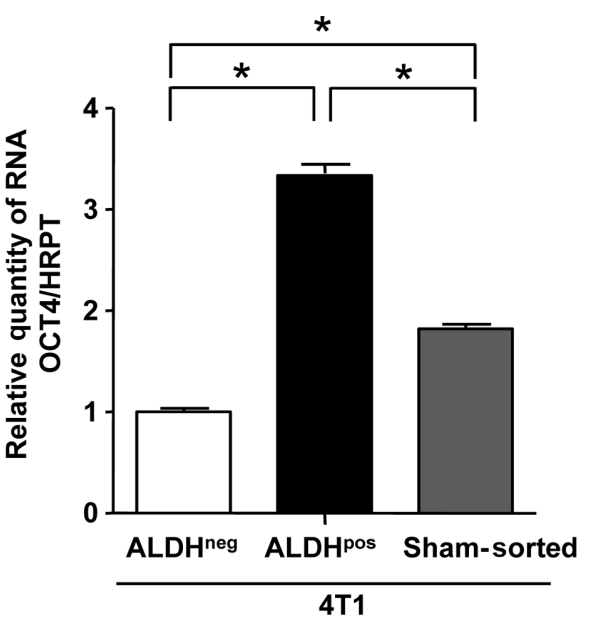

B.

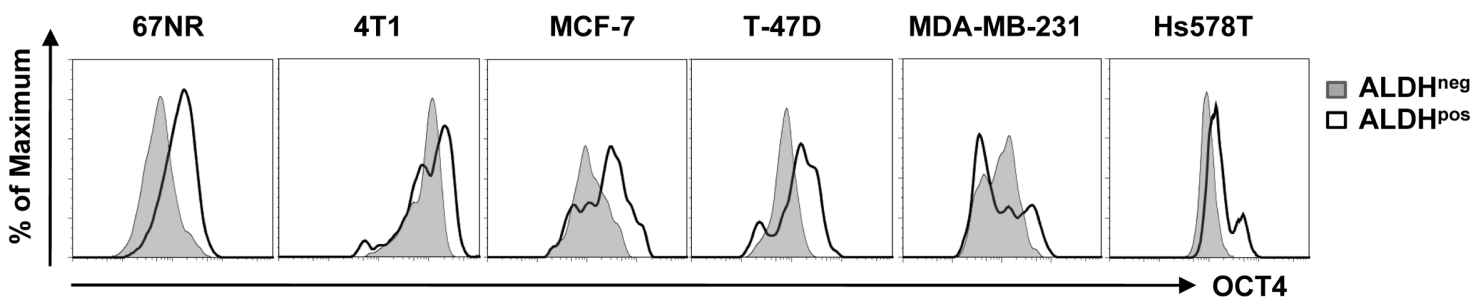

\begin{tabular}{|c|c|c|c|c|c|c|}
\hline \multicolumn{7}{|c|}{ Expression of OCT4 (\%) } \\
\hline & $67 N R$ & $4 T 1$ & MCF-7 & T-47D & MDA-MB-231 & Hs578T \\
\hline ALDH $^{\text {neg }}$ & $2.94 \pm 0.74$ & $11.58 \pm 2.52$ & $13.65 \pm 2.34$ & $8.45 \pm 0.021$ & $1.53 \pm 0.31$ & $3.09 \pm 0.28$ \\
\hline ALDH $^{\text {pos }}$ & $11.23 \pm 2.53^{*}$ & $38.89 \pm 2.52^{*}$ & $48.27 \pm 2.23^{*}$ & $56.85 \pm 5.60^{*}$ & $8.09 \pm 0.67^{*}$ & $29.45 \pm 3.93^{*}$ \\
\hline
\end{tabular}

Figure 1. ALDH ${ }^{\text {pos }} 4 \mathrm{~T} 1$ cells show a large increase in OCT4 expression in breast cancer cells. (A) RTQ-PCR analysis of OCT4 in $\mathrm{ALDH}^{\text {neg }}$ and $\mathrm{ALDH} \mathrm{p}^{\mathrm{pos}} 4 \mathrm{~T} 1$ cells. Left panel, the contour plot shows the percentage of ALDH activity in $4 \mathrm{~T} 1$ cells. (B) Flow cytometry profiles of OCT4 expression on $A_{L D H}{ }^{\text {neg }}$ or ALDH $^{\text {pos }}$ cell population derived from breast cancer cell lines $(67 N R, 4 T 1, M C F-7, T-$ 47D, MDA-MB-231, and Hs578T). Values are mean \pm SD. ${ }^{*} P<0.05$ is a statistically significant difference.

be cultured in vitro to test stem cell properties such as selfrenewal in serum-free medium with bFGF and EGF [12]. To determine whether $4 \mathrm{~T} 1$ cells showing OCT $4^{\text {high }}$ have high sphere-forming ability, we introduced an OCT4-RFP vector into 4T1-Luc cells (Figure 1A), sorted 4T1-Luc cells into $\mathrm{OCT} 4^{\text {low }}$ and OCT $4^{\text {high }}$ cell population, and plated the freshly isolated cell populations under tumorsphere forming culture conditions (Figure 2A). Only the OCT $4^{\text {high }}$ cell population grew into typical spheres and they showed much larger and greater numbers of spheres than did the OCT ${ }^{\text {low }}$ cell population (Figure 2B).
OCT $4^{\text {high }} 4 \mathrm{~T} 1$ cell population has more tumorigenic potential in vivo in immune-competent mice

To investigate the in vivo tumorigenic ability of OCT4 $4^{\text {high }}$ cell population, we injected sorted cells into the mammary glands of mice. As shown in Table 1, OCT $4^{\text {high }} 4 \mathrm{~T} 1$-Luc cells gave rise to tumors in five of six inoculations (83.3\%) with as few as 100 cells. At the same injection dose (100 cells), OCT $4^{\text {low }} 4 \mathrm{~T} 1$-Luc cells gave rise to tumors in $16.6 \%$ of trials (one of six inoculations). The OCT $4^{\text {high }}$ cell population showed $\sim 5$-fold enrichment compared with the OCT4 ${ }^{\text {low }}$ cell population. At 100-cell inoculation, in vivo imaging showed 
A.

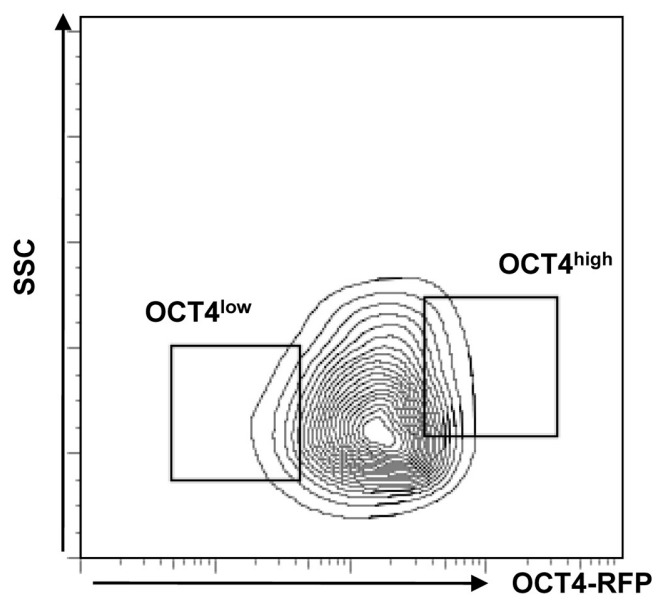

mOCT4-RFP
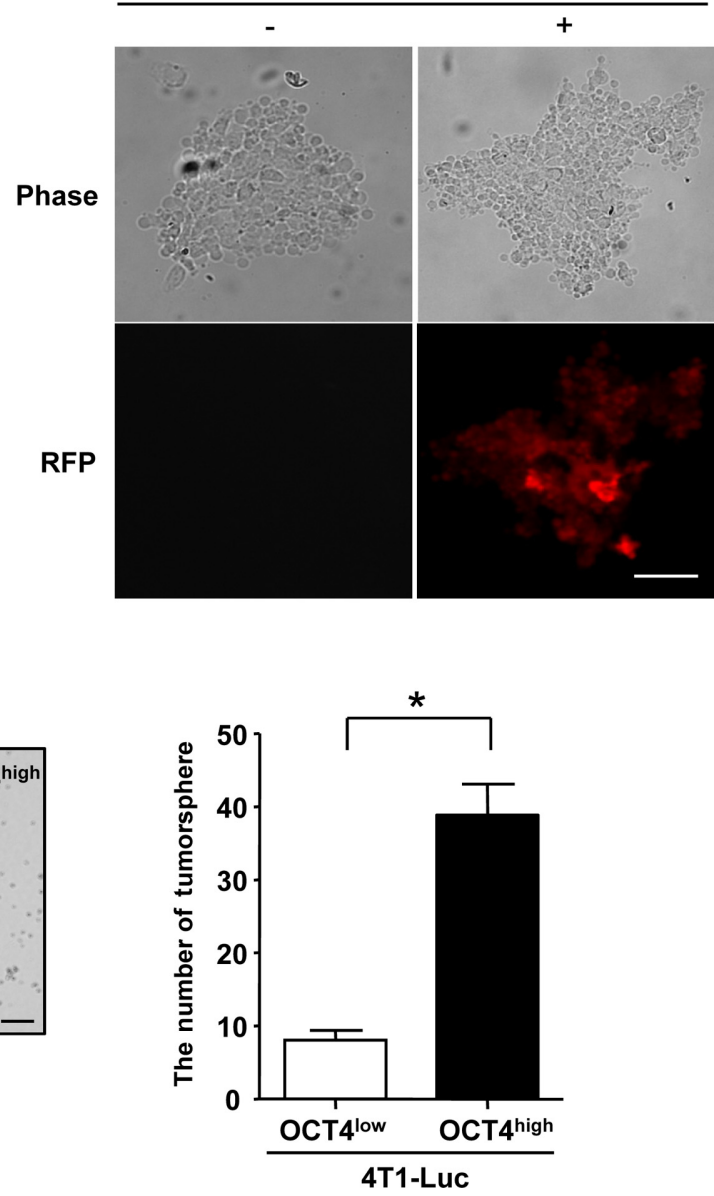

Figure 2. An OCT4 $4^{\text {high }}$ cell population isolated from 4T1-Luc cells has a high efficiency of tumorsphere formation in vitro. (A) The level of red fluorescence was determined in mOCT4-RFP infected 4T1-Luc cells using a fluorescence microscope. (B) The ability of OCT4 ${ }^{\text {low }}$ and OCT4 ${ }^{\text {high }} 4$ T1-Luc cells cultured in low attachment dishes to form spheres was determined as described in Materials and Methods. Values are mean \pm SD. ${ }^{*} P<0.05$ is a statistically significant difference.

Table 1. Tumor-initiating ability of the OCT $4^{\text {high }}$ cell population in the 4T1 syngeneic mouse model

\begin{tabular}{cccc}
\hline \multirow{2}{*}{ Cell type $^{\mathrm{a}}$} & \multicolumn{3}{c}{ Number of implanted cells } \\
\cline { 2 - 4 } & $1 \times 10^{3}$ & $3 \times 10^{2}$ & $1 \times 10^{2}$ \\
\hline OCT4 $^{\text {low }}$ & $3 / 6$ & $2 / 6$ & $1 / 6$ \\
OCT4 $^{\text {high }}$ & $5 / 6$ & $5 / 6$ & $5 / 6$ \\
\hline
\end{tabular}

These cells injected into mammary fat pad of Balb/c mice at varying initial cell counts.

an increase ( $\sim 2$-fold) in bioluminescence in the primary tumor generated by OCT $4^{\text {high }} 4 \mathrm{~T} 1$-Luc cells, compared with OCT $4^{\text {low }}$ 4T1-Luc cells (Figure 3). These results demonstrate that the OCT $4^{\text {high }}$ cell population has more tumorigenic potential in vivo in an immune competent microenvironment.

The OCT $4^{\text {high }} 4 \mathrm{~T} 1$ cell population has high expression of stem cell markers

To further characterize the OCT $4{ }^{\text {high }}$ cell population, we compared expression profiles of stem cell marker genes [1318] in OCT $4^{\text {low }}$ and OCT $4^{\text {high }}$ cell population sorted from 4T1-Luc cells. RTQ-PCR analysis showed significant increases ( 2-fold to 3-fold) for Sca-1, CD133, CD34 and ALDH1 expression but no significant change in CD90 expression in the OCT $4^{\text {high }}$ cell population over the OCT $4^{\text {low }}$ cell population (Figure 4). Taken together, these results show that the expression of stem cell markers is highly increased in the OCT4 $4^{\text {high }}$ cell population.

\section{Discussion}

The OCT4 gene, a member of the POU family of transcription factors, was shown to be expressed in stem cells $[19,20]$. In this study, we applied OCT4 positive cell analysis and sorting to cause enrichment in putative CSCs in the 4T1 mouse model. The $4 \mathrm{~T} 1$ breast cancer model is widely considered to be one of the best syngeneic xenograft mouse 


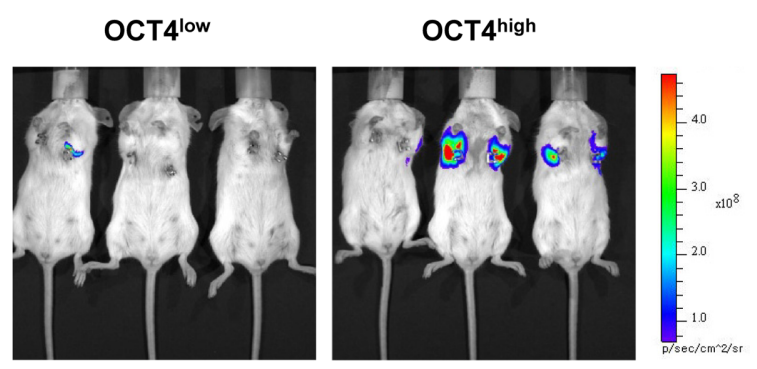

Cell No. of inoculation: 100

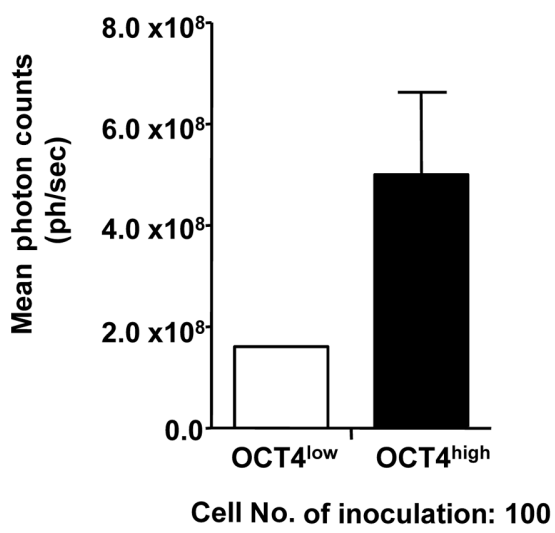

Figure 3. OCT4 ${ }^{\text {high }}$ 4T1-Luc cells have greater tumorigenic potential in vivo in immune-competent mice. Tumor growth was monitored and quantified by bioluminescence.

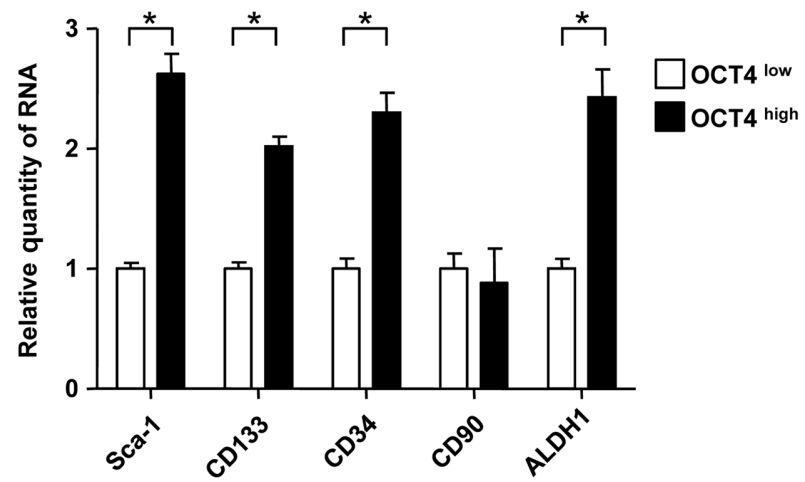

Figure 4. OCT4 $4^{\text {high }} 4 \mathrm{~T} 1$ cells isolated from $4 \mathrm{~T} 1$-Luc cells have high expression of stem cell markers. RTQ-PCR was performed using primers for stem cell markers. Values are mean $\pm S D$ for 3 determinations. ${ }^{*} P<0.05$ is a statistically significant difference.

models for the study of human cancer progression [21,22]. To our knowledge, this is the first report that OCT4 may be a good marker for CSC characterization in an immunecompetent syngeneic tumor microenvironment. This conclusion was supported by the following findings. First, the size of the OCT4 $4^{\text {high }}$ cell population isolated from 4T1 cells was positively correlated with tumorigenicity in immunecompetent mice compared with the OCT $4^{\text {low }}$ cell population. Second, CSCs expressing OCT4 displayed high tumorsphere forming ability in vitro. Third, the OCT $4^{\text {high }}$ cell population had high expression of stem cell markers compared with the OCT4 ${ }^{\text {low }}$ cell population.

Self-renewal and pluripotency are central features in the definition of stem cell populations, and OCT4 is a key regulator in these processes [19, 23]. Further, the expression of OCT4 has been shown in human breast cancer stem-like cells, implicating its involvement in self-renewal and tumorigenesis [24]. Recently, Hu and colleagues suggested that a reduction in OCT4 expression in lung CSCs induces apoptosis and the inhibition of tumor growth partly through the OCT4/Tcl1/ Akt1 pathway [8]. In addition, OCT4 was recently reported to play a critical role in survival/apoptosis of embryonic stem cells via stat3/survivin [25]. However, the detailed molecular roles of OCT4 in cancer stemness have not yet been fully elucidated. Therefore, additional studies are necessary to look into downstream molecular mechanisms by which OCT4 regulates the maintenance and expansion of CSCs.

In summary, the present work suggests that high expression of OCT4 enhances stem cell properties in a mouse model of breast cancer. Thus, OCT4 may represent a target molecule for the treatment of advanced cancer.

\section{Acknowledgment}

This work was supported by the Korea Research Foundation Grant funded by the Korean Government (MOEHRD, Basic Research Promotion Fund) (KRF-2008-331-E00259).

\section{References}

1. Dean M, Fojo T, Bates $S$. Tumour stem cells and drug resistance. Nat Rev Cancer 2005; 5(4): 275-284.

2. Charafe-Jauffret E, Monville F, Ginestier C, Dontu G, Birnbaum D, Wicha MS. Cancer Stem Cells in Breast: Current Opinion and Future Challenges. Pathobiology 2008; 75(2): 75-84.

3. Gangemi R, Paleari L, Orengo AM, Cesario A, Chessa L, Ferrini $S$, et al. Cancer stem cells: a new paradigm for understanding tumor growth and progression and drug resistance. Curr Med Chem 2009; 16(14): 1688-1703.

4. Hansis C, Grifo JA, Krey LC. Oct-4 expression in inner cell mass and trophectoderm of human blastocysts. Mol Hum Reprod 2000; 6(11): 999-1004.

5. Burdon T, Smith A, Savatier P. Signalling, cell cycle and pluripotency in embryonic stem cells. Trends Cell Biol 2002; 12(9): 432-438.

6. Kim JB, Greber B, Arauzo-Bravo MJ, Meyer J, Park KI, Zaehres $\mathrm{H}$, et al. Direct reprogramming of human neural stem cells by OCT4. Nature 2009; 461(7264): 649-653. 
7. Chang CC, Shieh GS, Wu P, Lin CC, Shiau AL, Wu CL. Oct$3 / 4$ expression reflects tumor progression and regulates motility of bladder cancer cells. Cancer Res 2008; 68 (15): 6281-6291.

8. Hu T, Liu S, Breiter DR, Wang F, Tang Y, Sun S. Octamer 4 small interfering RNA results in cancer stem cell-like cell apoptosis. Cancer Res 2008; 68(16):6533-6540.

9. Nam JS, Kang MJ, Suchar AM, Shimamura T, Kohn EA, Michalowska AM, et al. Chemokine (C-C motif) ligand 2 mediates the prometastatic effect of dysadherin in human breast cancer cells. Cancer Res 2006; 66(14):7176-7184.

10. Nam JS, Suchar AM, Kang MJ, Stuelten CH, Tang B, Michalowska AM, et al. Bone sialoprotein mediates the tumor cell-targeted prometastatic activity of transforming growth factor beta in a mouse model of breast cancer. Cancer Res 2006; 66(12):6327-6335.

11. Choi ES, Cho SD, Jeon JG, Cho NP. The Apoptotic Effect of the Hexane Extract of Rheum undulatum L. in Oral Cancer Cells through the Down-regulation of Specificity Protein 1 and Survivin. Lab Anim Res 2011; 27(1): 19-24.

12. Dontu G, Abdallah WM, Foley JM, Jackson KW, Clarke MF, Kawamura MJ, et al. In vitro propagation and transcriptional profiling of human mammary stem/progenitor cells. Genes Dev 2003; 17(10): 1253-1270.

13. Kim RJ, Kim SR, Roh KJ, Park SB, Park JR, Kang KS, et al. Ras activation contributes to the maintenance and expansion of Sca-1pos cells in a mouse model of breast cancer. Cancer Lett 2010; 287(2): 172-81.

14. Ginestier C, Hur MH, Charafe-Jauffret E, Monville F, Dutcher J, Brown $M$, et al. ALDH1 Is a Marker of Normal and Malignant Human Mammary Stem Cells and a Predictor of Poor Clinical Outcome. Cell Stem Cell 2007; 1(5): 555-567.

15. Bao S, Wu Q, McLendon RE, Hao Y, Shi Q, Hjelmeland AB, et al. Glioma stem cells promote radioresistance by preferential activation of the DNA damage response. Nature 2006; 444(7120): 756-760.

16. Bonnet D, Dick JE. Human acute myeloid leukemia is organized as a hierarchy that originates from a primitive hematopoietic cell. Nat Med 1997; 3(7): 730-737.

17. Welm BE, Tepera SB, Venezia T, Graubert TA, Rosen JM, Goodell MA. Sca-1(pos) cells in the mouse mammary gland represent an enriched progenitor cell population. Dev Biol 2002; 245(1): 42-56.

18. Yang ZF, Ho DW, Ng MN, Lau CK, Yu WC, Ngai $P$, et al. Significance of $\mathrm{CD} 90+$ cancer stem cells in human liver cancer. Cancer Cell 2008; 13(2): 153-166.

19. Nichols J, Zevnik B, Anastassiadis K, Niwa H, KleweNebenius D, Chambers I, et al. Formation of pluripotent stem cells in the mammalian embryo depends on the POU transcription factor Oct4. Cell 1998; 95(3): 379-391.

20. Babaie Y, Herwig R, Greber B, Brink TC, Wruck W, Groth D, et al. Analysis of Oct4-dependent transcriptional networks regulating self-renewal and pluripotency in human embryonic stem cells. Stem Cells 2007; 25(2): 500-510.

21. Kuperwasser C, Chavarria T, Wu M, Magrane G, Gray JW, Carey $\mathrm{L}$, et al. Reconstruction of functionally normal and malignant human breast tissues in mice. Proc Natl Acad Sci USA 2004; 101(14): 4966-4971.

22. Lelekakis M, Moseley JM, Martin TJ, Hards D, Williams E, Ho $\mathrm{P}$, et al. A novel orthotopic model of breast cancer metastasis to bone. Clin Exp Metastasis 1999; 17(2): 163170.

23. Boiani M, Scholer HR. Regulatory networks in embryoderived pluripotent stem cells. Nat Rev Mol Cell Biol 2005; 6(11): 872-884.

24. Ponti D, Costa A, Zaffaroni N, Pratesi G, Petrangolini G, Coradini $\mathrm{D}$, et al. Isolation and in vitro propagation of tumorigenic breast cancer cells with stem/progenitor cell properties. Cancer Res 2005; 65(13): 5506-5511.

25. Guo Y, Mantel C, Hromas RA, Broxmeyer HE. Oct-4 is critical for survival/antiapoptosis of murine embryonic stem cells subjected to stress: effects associated with Stat3/survivin. Stem Cells 2008; 26(1): 30-34. 